\section{Palliative care approach to oncological patient - Main points}

\author{
Muhammed Emin Göktepe ${ }^{1}$, Onur Öztürk* and Mustafa Ünal ${ }^{2}$ \\ 'Department of Family Medicine, SBU Samsun Education and Research Hospital, Turkey \\ ${ }^{2}$ Department of Family Medicine, Faculty of Medicine, Ondokuz Mayis University, Turkey
}

\section{Dear Editor,}

According to the World Health Organization definition, palliative care is an approach aimed at increasing the quality of life of patients and their relatives by addressing physical, psychosocial and spiritual needs and treating conditions early, such as pain while they are coming to terms with a lifethreatening disease [1]. Palliative care services have started a rapid progress in developed countries such as Scandinavian countries, England and Canada since the beginning of 1990 [2].

Although palliative care cares for any patient who is in need of care, whether bed-bound or unable to look after themselves, one of the main area of interest is of course oncological patients and their relatives. Patients with advanced cancer, frequent sufferings from physical and psychological symptoms primarily pain, reduced functional capacity, and reduced quality of life are in the scope of palliative care protocol [3].

The most common end-of-life symptoms and signs in palliative cancer patients are pain, anorexia, nausea, cachexia, weakness, dyspnea, ascites, anxiety, agitation, delirium, confusion and pressure sores. In order to achieve quality and continuous care in case management, a family doctor, specific branch specialist, nurse, dietician, psychologist, cleric, etc. should work together in a multidisciplinary approach and clinical guidelines and care protocols should be implemented [4]. However, it should be kept in mind that increasing the medication dose may not always be beneficial to the oncological patients in palliative services. The goal should always be maximum benefit with minimal tests and treatment.

Palliative care does not aim to accelerate or postpone death; but it has many benefits in cancer patients and their relatives including the integration of the psychosocial and spiritual aspects of patient care into physical care, providing support for patients to live as active as possible until the last moment, improving the quality of life and the disease process, providing help and support in the grieving process $[1,5]$.

Providing good care to advanced cancer patients requires that caregivers are educated and supported about their

\section{More Information}

*Address for Correspondence: Onur Öztürk, SBU Samsun Education and Research Hospital, Department of Family Medicine, Turkey, Tel: +905547536566; Email: dr.onurozturk@yahoo.com

Submitted: 20 March 2020

Approved: 30 March 2020

Published: 31 March 2020

How to cite this article: Göktepe ME, Öztürk O, Ünal M. Palliative care approach to oncological patient - Main points. Arch Cancer Sci Ther. 2020; 4: 015-016.

DOI: 10.29328/journal.acst.1001015 ORCiD: orcid.org/0000-0002-3371-6051

Copyright: @ 2020 Göktepe ME, et al. This is an open access article distributed under the Creative Commons Attribution License, which permits unrestricted use, distribution, and reproduction in any medium, provided the original work is properly cited.

Check for updates

( $)$ OPEN ACCESS

patients' physical, psychological and social care needs. Balancing the physical and emotional needs of the caregivers will reduce the stress they experience, as well as increase the quality of life of their patients [6,7]. Professionalism in palliative care comes into play right at this point.

There is no consensus in the medical world about by whom, when and to whom palliative care should be given. In this regard, the conflicts of opinion between specific branches such as anesthesia, internal medicine and neurology are inevitable. We think that the team leader should be a family physician or a palliative care specialist. The reason for this is the family medicine's principles of core competencies including biopsycosocial, holistic, comprehensive approach and equal distance to specific branches. Of course when the palliative care specialist is the team leader the patient's own family doctor still provides invaluable service because of his intimate and long-term knowledge about the patients.

One key difference in some countries is that no distinction is being made between palliative and hospice care. Neither the insurance companies nor the state demands such classification because it doesn't serve any practical purpose at the moment. However, in due time such distinction will be inevitable as one of the cost-cutting measure. Medical oncology will have to report about the expected survival of the cancer patients and it will further increase their workload given the exponential increase in cancer cases. 


\section{References}

1. World Health Organization (WHO). Definition of palliative care. 2020.

2. Klaschik E. Palliativmedizin. Praktische Einführung in Schmerztherapie, Symptomkontrolle, Ethik und Kommunikation 'de. Eds. Huseb $\varnothing$, Stein and Klaschik E. Berlin. 2000; 1-33.

3. National Comprehensive Cancer Network NCCN Clinical Practice Guidelines in Oncology. 2009

4. Aydoğan F, Uygun K. Kanser hastalarında palyatif tedaviler. Klinik Gelişim. 2011; 4-9.
5. Hacialioglu N, Ozer N, Yilmaz Karabulutlu E, Erdem N, Erci B. The quality of life of family caregivers of cancer patients in the east of Turkey. Eur J Oncol Nurs. 2010; 14: 211-217.

PubMed: https://www.ncbi.nlm.nih.gov/pubmed/20149734

6. Kabalak AA, Öztürk $H$, Çağıl $H$. Yaşam sonu bakım organizasyonu; palyatif bakım. Yoğun Bakım Dergisi. 2013; 11: 56-70.

7. Kim Y, Given BA. Quality of life of family caregivers of cancer survivors: across the trajectory of the illness. Cancer. 2008; 112: 2556-2568. PubMed: https://pubmed.ncbi.nlm.nih.gov/18428199/ 